Article

\title{
Comparison of Manganese Dioxide and Permanganate as Amendments with Persulfate for Aqueous 1,4-Dioxane Oxidation
}

\author{
Logan Bridges ${ }^{1,2}$, Ruba A. M. Mohamed $^{2}$, Naima A. Khan ${ }^{2}$, Mark L. Brusseau ${ }^{3}$ \\ and Kenneth C. Carroll 1,2,*(D) \\ 1 Water Science and Management Program, New Mexico State University, MSC 3Q P.O. Box 30003, \\ Las Cruces, NM 88003, USA; loganbridges51@gmail.com \\ 2 Plant \& Environmental Science Department, New Mexico State University, MSC 3Q P.O. Box 30003, \\ Las Cruces, NM 88003, USA; rmohamed@nmsu.edu (R.A.M.M.); linda29@nmsu.edu (N.A.K.) \\ 3 Department of Soil, Water, Environmental Science, University of Arizona, Tucson, AZ 85721, USA; \\ brusseau@arizona.edu \\ * Correspondence: kccarr@nmsu.edu
}

Received: 1 October 2020; Accepted: 29 October 2020; Published: 1 November 2020

\begin{abstract}
Persulfate (PS) is widely used to degrade emerging organic contaminants in groundwater and soil systems, and various PS activation methods (e.g., energy or chemical inputs) have been considered to increase oxidation strength. This study investigates PS activation through manganese amendment in the form of potassium permanganate $\left(\mathrm{KMnO}_{4}\right)$ and manganese dioxide $\left(\mathrm{MnO}_{2}\right)$ to subsequently degrade the emerging and recalcitrant groundwater contaminant 1,4-dioxane (1,4-D). The activation of PS by $\mathrm{MnO}_{2}$ was confirmed by radical trap and by product formation. The degradation kinetics of 1,4-D by PS was also compared with varying amendments of $\mathrm{KMnO}_{4}$ and $\mathrm{MnO}_{2}$. The results showed that $\mathrm{MnO}_{2}$ activated PS, which increased the degradation rate constant of 1,4-D. $\mathrm{KMnO}_{4}$ activation of PS was not observed even though the binary oxidant mixture did enhance the degradation of 1,4-D. These results have implications for applying in situ chemical oxidation in subsurface systems, especially for conditions wherein manganese exists naturally in groundwater or aquifer minerals to support possible PS activation.
\end{abstract}

Keywords: persulfate; 1,4-dioxane; advanced oxidation; permanganate; manganese dioxide; ISCO; groundwater contamination; groundwater remediation

\section{Introduction}

1,4-Dioxane (1,4-D) is a recalcitrant and emerging water contaminant that was commonly used as a solvent stabilizer mixed with chlorinated solvents, mainly 1,1,1-trichloroethane (TCA) and trichloroethene (TCE), and co-disposal has resulted in groundwater contamination [1-3]. 1,4-D is hazardous to humans, and it was classified as a probable human (B2) carcinogen [2,4-7]. Due to the relatively high polarity and miscibility with water and low volatilization of $1,4-\mathrm{D}$, there are limited options for treatment, which has enabled development of extensive wastewater impacts and groundwater contaminant plumes. 1,4-D is not generally removed from groundwater and wastewater using standard technologies typically used for chlorinated co-contaminant treatment [1,3,8-11]. Pollitt, Kim [12] provide a recent review of the health risks, contaminant remediation issues, and additional research needs.

Degradation and removal of 1,4-D from contaminated water has been demonstrated through application of strong oxidants or advanced oxidation processes (AOP) $[1,8,9,13]$. The persulfate ion (PS) has been proposed for in-situ chemical oxidation (ISCO) of groundwater plumes because 
of the increased aqueous solubility and stability advantage PS has over other regularly used AOP oxidants such as catalyzed $\mathrm{H}_{2} \mathrm{O}_{2}$ propagation and ozone [14]. Because of the symmetric structure of PS molecules, nonactivated PS exhibits a relatively low oxidation potential $\left(\mathrm{E}^{\mathrm{o}}=2.1 \mathrm{~V}\right)$ for AOP $[15,16]$. PS activation (i.e., catalysis to form free sulfate radicals $\left(\mathrm{SO}_{4}^{\bullet-}\right)$ ) is generally considered for oxidation of recalcitrant organic contaminants $[17,18]$. Upon activation, persulfate becomes a stronger oxidant, through the generation of sulfate radicals $\left(\mathrm{E}^{\mathrm{O}}=2.6 \mathrm{~V}\right)$ that can effectively decompose recalcitrant organic contaminants $[16,18]$.

Various methods including heat, UV irradiation, ultrasonication, and electrochemical activation are used to activate PS and generate sulfate radicals [19]. However, these approaches for activation are challenging for ISCO applications due to subsurface inaccessibility. Transition metals and carbon-based graphene alternatives have also recently been proposed [18,20-24]. The release of toxic metal catalysts during ISCO treatment is a significant concern for the former, and relatively high amendment costs are an issue for the latter. Ferrous iron $\left(\mathrm{Fe}^{2+}\right)$ is the most common transition metal catalysis and a readily available activator, with common forms being ferrous sulfate and ferrous chloride. Aqueous-iron activation of PS using $\mathrm{Fe}^{2+}$ is typically observed as a homogeneous, first-order process. Although $\mathrm{Fe}^{2+}$ is one of the most widely used nontoxic activation agents for above-ground applications, its effectiveness is often limited in subsurface applications due to aqueous-availability constraints associated with iron speciation and cycling [25]. To overcome iron-availability constraints, a solid form of iron can be used. For example, Zhong, Brusseau [25] used iron filings to activate PS and transform 1,4-D. A two-stage reaction mechanism was proposed to describe the oxidation process by iron activated PS, consisting of a first stage of rapid, solution-based, radical-driven decomposition of 1,4-D and a second stage governed by rate limited surface reaction [25]. For effective PS activation, generally, an iron solid-liquid ratio of 1:10 (weight/weight) was required [25]. However, an excess of iron greater than $750 \mathrm{mg} / \mathrm{L}$ led to the rapid decomposition of PS and a loss of potential remediation [25].

Recently, there has been a significant increase in interest and in investigations focused on persulfate-based advanced oxidation including activation through redox reactions with subsurface minerals [26-32]. In natural systems including aquifers and soil systems, ferrihydrite, goethite, iron containing minerals, and nontronite, an iron-rich clay, were found to decompose PS [26,27,29,33-35]. Specifically, PS is activated by $\mathrm{Fe}^{2+}$ and $\mathrm{Mn}^{4+}$ containing oxide minerals through Fenton-like reactions that generate sulfate radicals. Montmorillonite, a clay with relatively high manganese content was found to decompose PS at a rate that was approximately an order of magnitude higher than that of nontronite [33]. Fang, Chen [29] examined the reaction and interaction mechanisms between PS and soil constituents. Zhu, Li [30] investigated nonradical aqueous contaminant degradation with PS activation on Mn oxides. Yan, Zhong [36] also examined the natural activation ability of subsurface media to promote in-situ contaminant oxidation, and they document the potential application for 1,4-D, and they found that iron species were primarily responsible for activation whereas Mn oxides likely contributed to the activation of PS. Use of minerals available in the subsurface as reagents for groundwater contamination cleanup is attractive, yet subsurface geochemical conditions (e.g., pH, alkalinity, chloride composition) need to be considered [35].

As one of the most common ISCO oxidants, the permanganate ion $\left(+7\right.$ oxidation state; $\left.\mathrm{E}^{\mathrm{o}}=1.7 \mathrm{~V}\right)$ is a relatively stable oxidant, soluble, and effective for oxidation of numerous organic contaminants in soil and groundwater [16]. However, it is not reactive enough to be considered an AOP oxidizing agent and may not be effective for the more inert or recalcitrant contaminants. $\mathrm{KMnO}_{4}$ has generally been considered too slow to effectively degrade 1,4-D [6]. ISCO of other organic contaminants using $\mathrm{KMnO}_{4}$ generates benign byproducts such as carbon dioxide gas and bicarbonate ions, manganese dioxide $\left(\mathrm{MnO}_{2}\right)$ precipitates, and salts. Additionally, the $\mathrm{MnO}_{2}$ byproduct (i.e., a $\mathrm{Mn}^{\mathrm{IV}+}$ oxide mineral) from the oxidation reaction can result in pore-filling with $\mathrm{MnO}_{2}$ mineral-precipitation [37-46]. Thus, injection of aqueous $\mathrm{KMnO}_{4}$ for ISCO increases the manganese content in groundwater; upon oxidation of organics it would also amend the solid subsurface aquifer materials with manganese oxides. This may 
support in situ activation of PS to enhance ISCO of recalcitrant contaminants, including 1,4-D, if the amended manganese solid minerals could act as an aqueous PS activator.

The objective of this study was to examine the feasibility of using manganese in the form of $\mathrm{MnO}_{4}{ }^{-}$or $\mathrm{MnO}_{2}$ as an amendment with PS in aqueous solutions to enhance the oxidative removal of 1,4-D from contaminated water. We quantified and compared removal kinetics for 1,4-D with and without $\mathrm{MnO}_{4}{ }^{-}$or $\mathrm{MnO}_{2}$ over a range of $\mathrm{Mn}, \mathrm{PS}$, and 1,4-D concentrations, and the results have implications for ISCO treatment of recalcitrant groundwater contaminants.

\section{Materials and Methods}

\subsection{Materials}

Acrylonitrile was used as purchased (Sigma-Aldrich; CAS \# 10713-1; part no. 110213; purity: 35-45 ppm monoethyl ether hydroquinone as inhibitor). Manganese dioxide was also used as purchased (Flinn Scientific Inc. CAS\# 1313-13-9; part no. M0026; formula wt. 86.94; 99.5\%; laboratory grade powder; particle size: 200 mesh; black or silver crystals or powder. Specific gravity: 5.026). The chemicals used to prepare the aqueous solutions included reagent grade 1,4-D $\left(\mathrm{C}_{4} \mathrm{H}_{8} \mathrm{O}_{2}, \geq 99.5 \%\right.$, Sigma Aldrich), sodium persulfate $\left(\mathrm{Na}_{2} \mathrm{~S}_{2} \mathrm{O}_{8}, 98 \%\right.$, Alfa Aesar), potassium iodide (KI, $\geq 99 \%$, Sigma Aldrich), potassium sulfate $\left(\mathrm{K}_{2} \mathrm{SO}_{4}, 99.2 \%\right.$, J.T. Baker), l-ascorbic acid $\left(\mathrm{C}_{6} \mathrm{H}_{8} \mathrm{O}_{6}, 99 \%\right.$, Sigma Aldrich), sodium bicarbonate $\left(\mathrm{NaHCO}_{3}, \geq 99 \%\right.$, Sigma Aldrich), and potassium permanganate $\left(\mathrm{KMnO}_{4},>99 \%\right.$, Acros Organics). For all experiments, a Barnstead NANOpure II (Series 550, Dubuque, Iowa) system was used to purify reverse osmosis water to $>18 \mathrm{M} \Omega-\mathrm{cm}$, which was then used (hereafter termed DI water) to prepare all solutions.

\subsection{1,4-Dioxane Degradation Batch Experiments}

Batch, kinetic experiments were performed to measure loss of PS through activation and loss of 1,4-D through oxidation in $1 \mathrm{~L}$ amber glassware or clear glassware covered in aluminum foil to prevent UV interaction with solution. Reaction solutions were prepared by adding oxidizing agents (PS or $\mathrm{KMnO}_{4}$ ) and $0.5 \mathrm{mM}$ 1,4-D into the reaction solution container, and $\mathrm{MnO}_{2}$ was added as an amendment to a series of reactors. The experimental reaction solution containers were placed on a rotating table set at 300 RPM. At specified times, samples were collected and the $\mathrm{pH}$ was measured (Accumet AB200 meter, Fisher Scientific, Waltham, MA, USA). For 1,4-D sample collection, $5 \mathrm{~mL}$ of $1 \mathrm{M}$ 1-ascorbic acid (oxidant quenching preservative) was placed in a $20 \mathrm{~mL}$ solid phase micro extraction (SPME) clear glass screw cap vial, followed by $5 \mathrm{~mL}$ of sample solution. Controls were prepared without PS for $0.5 \mathrm{mM} 1,4-\mathrm{D}$ and $0.5 \mathrm{mM}$ 1,4-D with $100 \mathrm{~g} / \mathrm{L} \mathrm{MnO}_{2}$ without PS. All the experiments were conducted at an ambient temperature of $21 \pm 2{ }^{\circ} \mathrm{C}$ in sealed reactor vials with headspace. 1,4-D experimental samples were collected and analyzed in triplicate, except the experiment for $0.5 \mathrm{mM} 1,4$-D decay with $49 \mathrm{mM}$ sodium persulfate that had the entire experiment replicated (i.e., set 1 and 2). Acrylonitrile has been generally used as a free radical polymerization agent [47]. A $1 \%$ of acrylonitrile by volume solution was created with $17.387 \mathrm{~g} / \mathrm{L} \mathrm{MnO}$ with $250 \mathrm{mM}$ PS, and another $1 \%$ acrylonitrile solution was created with $200 \mathrm{~g} / \mathrm{L} \mathrm{KMnO}_{4}$ with $49 \mathrm{mM}$ PS.

Sorption, as loss from aqueous solution, of 1,4-D to $\mathrm{MnO}_{2}$ was determined to be negligible (data not shown). Thus, contaminant removal (i.e., oxidation and degradation) was quantified by loss from aqueous solution. The natural log of the relative concentration (i.e., normalized by initial concentration, $\mathrm{C}_{\mathrm{o}}$ ) was plotted versus time, the slope was determined as the pseudo 1st order rate constant (i.e., $k\left(\mathrm{~h}^{-1}\right)$ ) by linear regression [48], and the mean values and standard deviations of rate constants were quantified using the regression analysis.

\subsection{Gas Chromatography_Time of Flight_Mass Spectrometry}

1,4-D chemical analysis was conducted using gas chromatography with mass spectrometry. A CTC Analytics CombiPAL Autosampler fitted with a solid phase micro extraction (SPME) fiber $(85 \mu \mathrm{m}$ 
Carboxen-Polydimethylesiloxane metal fiber) was used to collect and deliver samples. Each sample was incubated for $5 \mathrm{~min}$ at $55^{\circ} \mathrm{C}$ and then extracted for $5 \mathrm{~min}$. Then, the fiber had a 4 -min desorption time in the injector, which was fitted with a septaless Merlin Microseal. After the 5-min sample collection, the sample was delivered to a 7890A Agilent Gas Chromatograph fitted with a ZB-5MS column (30 m, $0.25 \mathrm{~mm}$ I.D., $0.25 \mu \mathrm{m}$ film thickness) with helium as the carrier gas. The inlet was in 10 to 1 split mode with a constant flow of $1.3 \mathrm{~mL} / \mathrm{min}$ with a front inlet septum purge of $3 \mathrm{~mL} / \mathrm{min}$. The inlet was operated at a constant $310{ }^{\circ} \mathrm{C}$ and the transfer line was constant at $250{ }^{\circ} \mathrm{C}$. The oven program started at $50{ }^{\circ} \mathrm{C}$ and held for $1.5 \mathrm{~min}$, ramped to $250{ }^{\circ} \mathrm{C}$ at $16{ }^{\circ} \mathrm{C} / \mathrm{min}$. A Leco Pegasus High Throughput Time of Flight Mass Spectrometer (TOF-MS) detector was used for 1,4-D sample analyses after a solvent delay of $0.25 \mathrm{~min}$. Compound masses were measured from $55-550 \mathrm{~m} / \mathrm{z}$ with an acquisition rate of 10 spectra/s operating at $70 \mathrm{eV}$, and the ion source heated at $250{ }^{\circ} \mathrm{C}$. Each peak was integrated using the Leco ChromaTof software version 4.41. 1,4-D was determined by the use of a commercial standard, and also matched to the National Institute of Standard and Technology (NIST) library. Samples were quantified by standard curve ranging from $0.025 \mathrm{mM}$ to $1.5 \mathrm{mM}$, and the lower detection limit using GC-ToF-MS analysis for 1,4-D was $0.02 \mathrm{mM}$.

\subsection{Scanning Electron Microscopy}

Solid $\mathrm{MnO}_{2}$ images and data were captured using a Scanning Electron Microscope (SEM) 3400N VP (Hitachi, Chiyoda, Tokyo, Japan). The SEM was equipped with a tungsten filament allowing accelerating voltages up to $30 \mathrm{kV}$. For element weight percentage analysis, Electron Dispersive X-ray Spectrometry (EDS) was used (Thermo Fisher Scientific, Waltham, MA, USA). Solid samples were dried under a vacuum before imaging and analysis. For solid $\mathrm{MnO}_{2}$ elemental percentage analysis, $7.9 \mathrm{~g} / \mathrm{L}$ of $\mathrm{MnO}_{2}$ were reacted with a range of PS concentrations (i.e., 5, 49, and $250 \mathrm{mM}$ of sodium PS) on a rotating table at 150 RPM for two weeks to ensure equilibration before EDS analysis. For comparison, $7.9 \mathrm{~g} / \mathrm{L}$ of $\mathrm{MnO}_{2}$ were also reacted with DI water as a control before EDS analysis of solid $\mathrm{MnO}_{2}$.

\subsection{Persulfate and Sulfate Anion Analyses}

The PS analysis was conducted using a spectrophotometric determination of PS based on modification of the iodometric titration method [49]. Experimental aqueous samples were filtered with a $0.45 \mu \mathrm{m}$ polyvinylidene fluoride (PVDF) prefilter (Filtermate, Environmental Express, Charleston, $\mathrm{SC}, \mathrm{USA}$ ) prior to analysis to prevent colorimetric analysis interference by $\mathrm{MnO}_{2}$ solids. The analysis stock solution was prepared to include $5 \mathrm{~g} / \mathrm{L}$ of sodium bicarbonate and $100 \mathrm{~g} / \mathrm{L}$ of potassium iodide equilibrated on a rotating table set at $300 \mathrm{RPM}$. A volume of $25 \mu \mathrm{L}$ of experimental sample was added to $10 \mathrm{~mL}$ stock solution. Then a SpectraMax M2 UV-Vis spectrophotometer (Molecular Devices, San Jose, CA, USA) was used for analysis, the spectra was measured at an absorbance of $400 \mathrm{~nm}$, and the lower detection limit of PS was $0.05 \mathrm{mM}$.

Sulfate analysis followed the HACH Sulfate SulfaVer 4 method where ions in solution react with barium in the HACH Sulfate SulfaVer 4 to form a precipitate of barium sulfate, and the amount of turbidity formed is proportional to the sulfate concentration. As noted above, samples were filtered prior to analysis using a $0.45 \mu \mathrm{m}$ PVDF prefilter (Filtermate, Environmental Express) to prevent analysis interference by $\mathrm{MnO}_{2}$ solids. SulfaVer4 Sulfate Reagent Powder Pillows were added to $10 \mathrm{~mL}$ of experimental sample. A SpectraMax M2 UV-Vis spectrophotometer (Molecular Devices) was used to analyze the samples at an absorbance of $450 \mathrm{~nm}$ (SulfateSulfaVer4 Method 10248, HACH Company, Loveland, CO, USA) method with a lower detection limit of $2 \mathrm{mg} / \mathrm{L}$.

\section{Results and Discussion}

\subsection{Activation of Persulfate}

Figure 1A presents the results of experiments including amendment of PS solutions with $\mathrm{MnO}_{2}$ at three different concentrations of $\mathrm{MnO}_{2}(0 \mathrm{~g} / \mathrm{L}, 17.4 \mathrm{~g} / \mathrm{L}$, and $100 \mathrm{~g} / \mathrm{L})$ with a fixed PS concentration 
(49 mM). PS activation was indicated both by its degradation and the formation of sulfate as a reaction product. As higher concentrations of $\mathrm{MnO}_{2}$ were added, a notable increase in the generation of sulfate by the end of the three-day period was observed. The production of sulfate occurred simultaneously with the decay of PS and provides additional confirmation of PS activation by $\mathrm{MnO}_{2}$. Without $\mathrm{MnO}_{2}$, PS degradation and sulfate production were both negligible in the control. Evaluation of PS activation using PS and sulfate measurement within $\mathrm{KMnO}_{4}$ solutions was not possible due to colorimetric interferences in the analysis methods. As $\mathrm{MnO}_{2}$ concentration increased, the pseudo 1st order rate constant values for PS decay and for sulfate production both increased (Figure 1B). The rate constant values were consistent with previously reported values for PS decay upon activation by the $\mathrm{MnO}_{2}$ mineral pyrolusite [33].
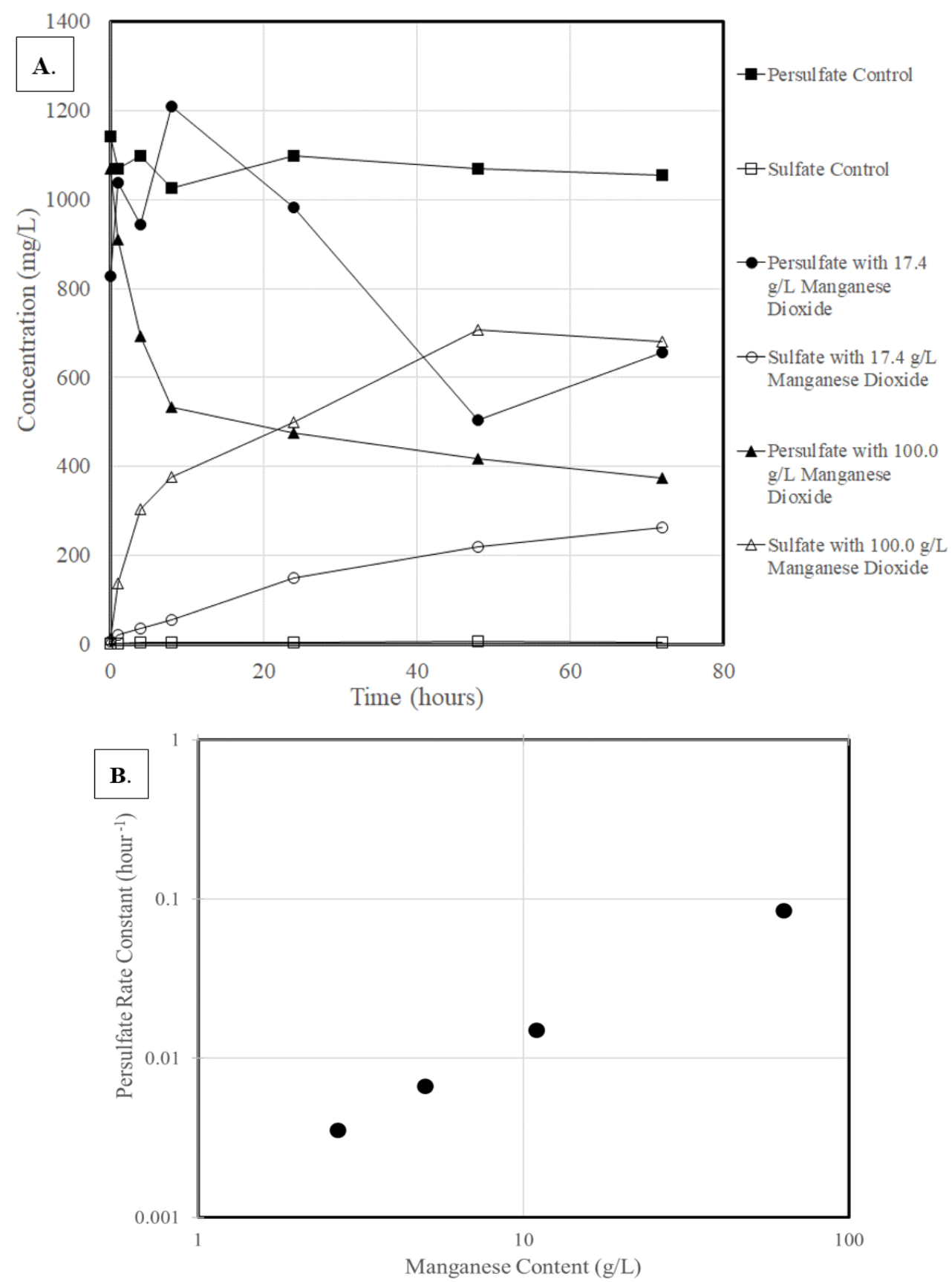

Figure 1. (A) Persulfate loss upon activation and sulfate product formation concentration as a function of time with different concentrations of $\mathrm{MnO}_{2}$. (B) Persulfate activation and decay pseudo 1st order rate coefficient as a function of $\mathrm{Mn}$ content. 
Radical formation was confirmed using acrylonitrile as a radical trap [47]. After approximately one hour, the solution with acrylonitrile, $\mathrm{MnO}_{2}$, and PS polymerized to form white clouds of precipitate (i.e., polymer formation through radical trap reaction) confirming radical formation in solution (Figure 2). Thus, activation of PS by $\mathrm{MnO}_{2}$ was confirmed by loss of persulfate, sulfate generation, and radical formation for solutions containing $\mathrm{MnO}_{2}$ and PS. However, the solution with acrylonitrile, $\mathrm{KMnO}_{4}$, and PS changed to a darker color without further polymer formation, which suggested radical formation and PS activation did not occur for solutions containing $\mathrm{KMnO}_{4}$.

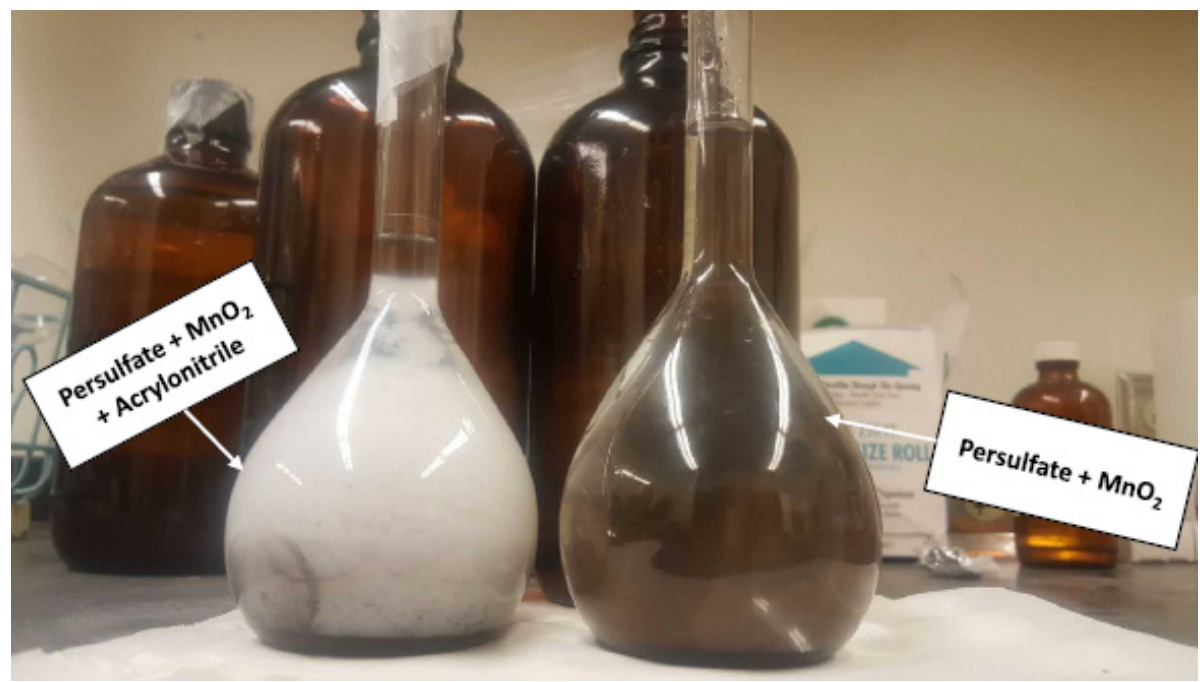

Figure 2. Picture of the persulfate (PS) in solution with addition of $\mathrm{MnO}_{2}$ with (left) and without (right) the addition of acrylonitrile to each solution. White acrylonitrile-polymer formation indicated radical formation for PS with $\mathrm{MnO}_{2}$.

These results suggest activation of PS through manganese amendment was limited to $\mathrm{MnO}_{2}$, and $\mathrm{KMnO}_{4}$ was inefficient as an activating agent for PS. There are significant differences in the manganese speciation for these two. For example, $\mathrm{MnO}_{2}$, is a solid mineral, and permanganate dissolves to form an aqueous ion in solution. Since both permanganate and PS dissolve into aqueous solution, and $\mathrm{MnO}_{2}$ is separated from aqueous PS as a separate phase, it might be expected that $\mathrm{KMnO}_{4}$ would be efficient as an activating agent for PS, but that was not the case, whereas, $\mathrm{MnO}_{2}$ was able to activate PS despite the differences in phases. This difference in reactivity was likely a result of differences in $\mathrm{Mn}$ oxidation state. $\mathrm{Mn}$ is in the +4 oxidation state within $\mathrm{MnO}_{2}$, and the $\mathrm{MnO}_{4}{ }^{-}$ion contains $\mathrm{Mn}$ in the +7 oxidation state.

\subsection{1,4-Dioxane Degradation}

Results for control experiments (Figure 3A), conducted without PS (i.e., 1,4-D control, $0.5 \mathrm{mM}$ 1,4-D with $100 \mathrm{~g} / \mathrm{L} \mathrm{MnO}_{2}$ ), indicted that negligible change in 1,4-D concentration was observed, which suggests that degradation of 1,4-D was negligible without the presence of $\mathrm{PS}$ or $\mathrm{MnO}_{4}$. Figure 3B shows the change in the relative concentration of 1,4-D with time when only PS was used as an oxidation agent. The change in concentration was negligible within the experiment containing only $5 \mathrm{mM}$ PS suggesting that a 1,4-D to PS mole ratio greater than 1:10 was required for the degradation. However, experiments containing $49 \mathrm{mM}$ and $250 \mathrm{mM}$ PS showed significant 1,4-D removal through oxidative transformation to the lower detection limit in less than $200 \mathrm{~h}$ from the beginning of the experiment (Figure 3), and these results confirm that PS can be used to rapidly remove 1,4-D from aqueous solutions. Elbs persulfate oxidation is the reaction of phenols with potassium persulfate [50], and with the structural similarity of phenol and 1,4-D, reactivity between 1,4-D and PS may follow the Elb oxidation reaction mechanism or a similar mechanism. 

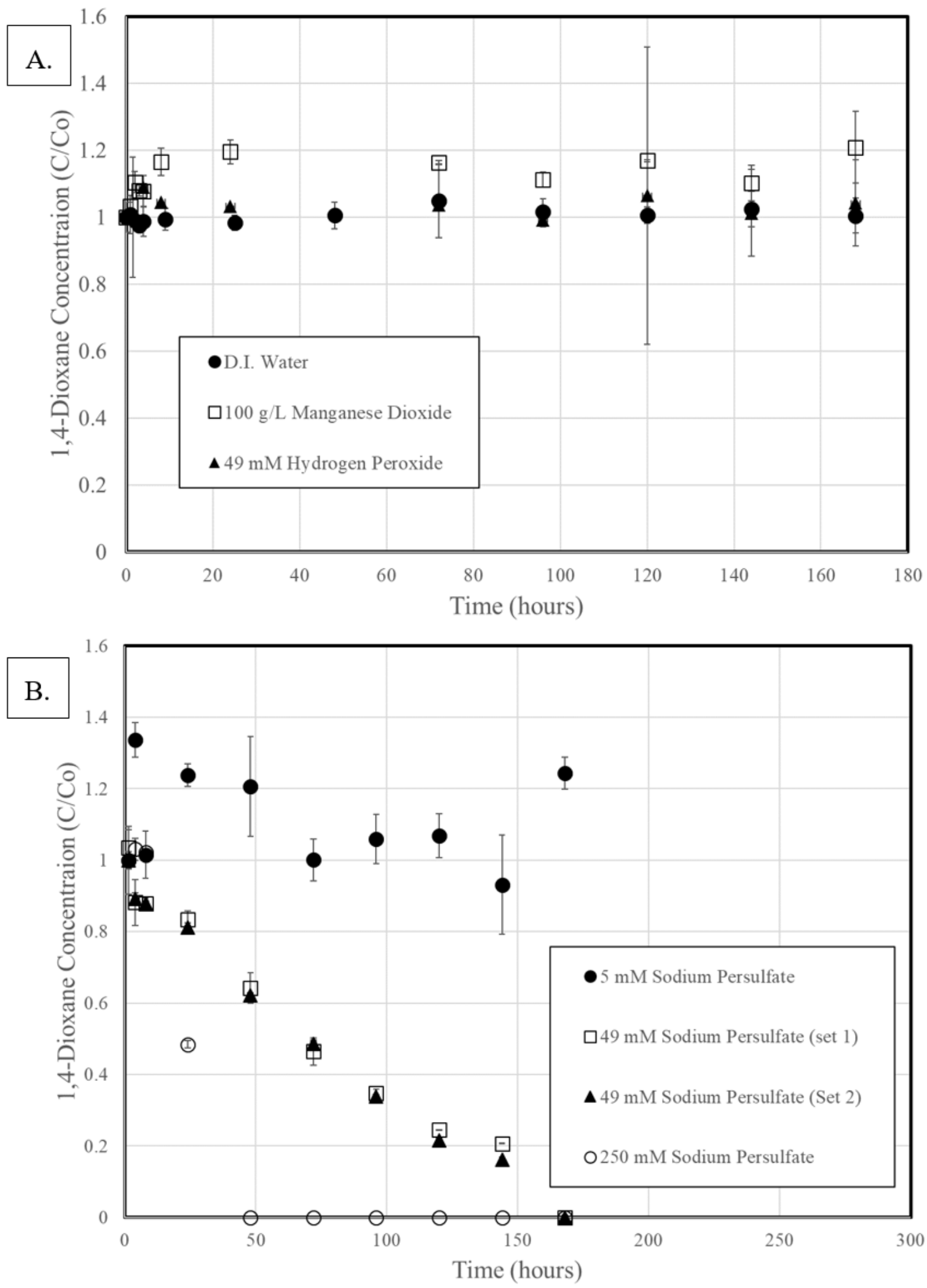

Figure 3. (A) Relative concentration as a function of time for control experiments, and (B) experiments used to quantify removal kinetics of 1,4-dioxane (1,4-D) using different persulfate concentrations (without manganese activation). Relative concentrations were normalized by the initial $0.5 \mathrm{mM} 1,4-\mathrm{D}$. Set 1 and 2 are replicate experiments. Error bars represent the standard deviation of triplicate samples. 
As shown in Figure 4, experiments containing both $\mathrm{PS}$ and $\mathrm{MnO}_{2}$ showed significant reduction of 1,4-D concentrations (typically to the lower detection limit of 1,4-D) in less than $200 \mathrm{~h}$ from the beginning of the experiment. In fact, degradation of 1,4-D was observed to increase as $\mathrm{MnO}_{2}$ amendment concentration was increased even when the PS concentration was constant (Figure 4; Table 1). However, the enhancement in 1,4-D decay was relatively minor, which suggests that $\mathrm{MnO}_{2}$ is not a very efficient activator for PS, which suggests that the activation mechanism may be acid catalysis. At $250 \mathrm{mM}$ PS and $17.4 \mathrm{~g} / \mathrm{L} \mathrm{MnO}_{2}$, 1,4-D completely degraded within 24-50 h.

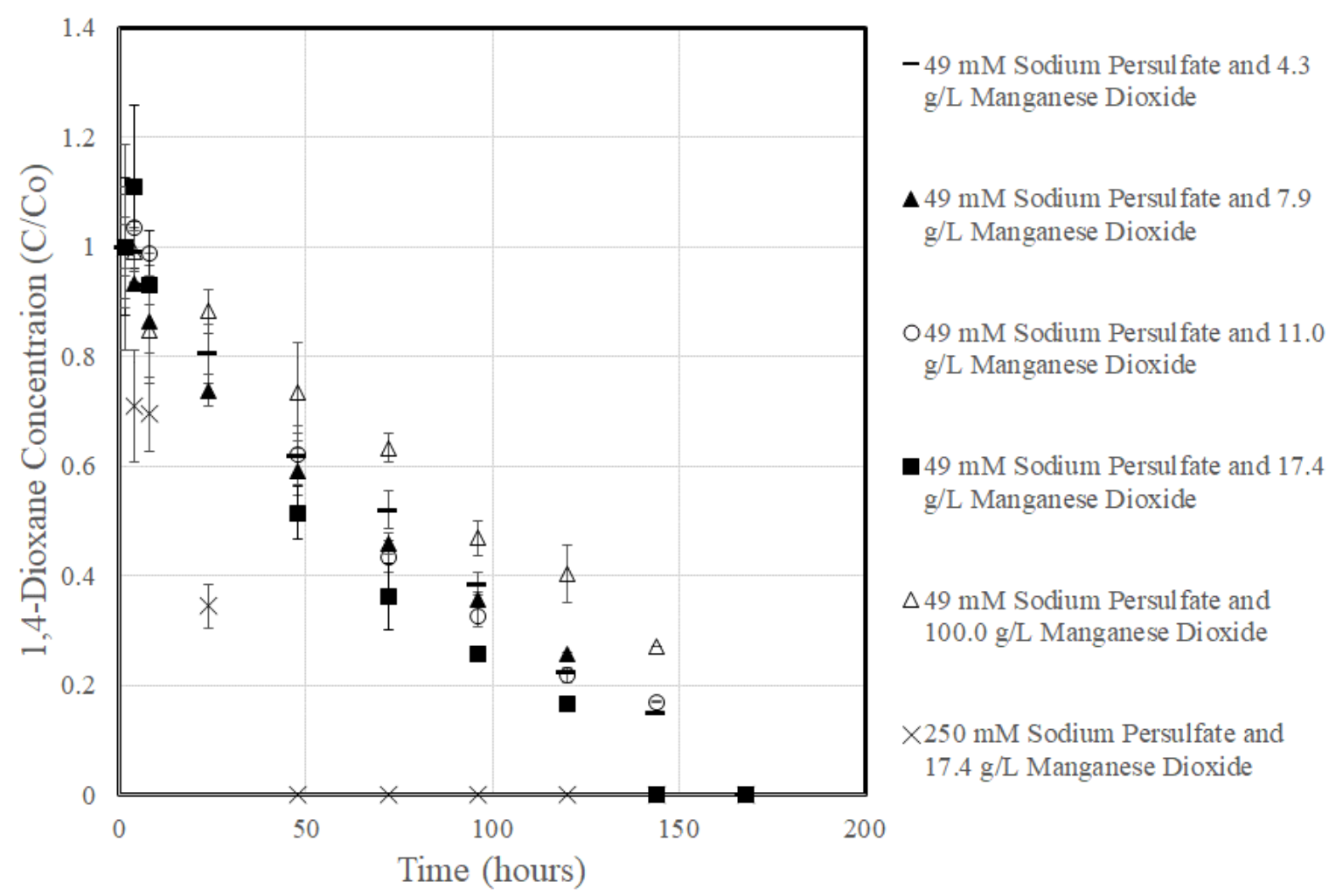

Figure 4. Relative concentration as a function of time illustrating removal kinetics of 1,4-D using PS with various $\mathrm{MnO}_{2}$ amendment amounts. Relative concentrations were normalized by the initial $0.5 \mathrm{mM}$ of 1,4-D. Error bars represent the standard deviation of triplicate samples.

Figure 5 shows four 1,4-D degradation experiments containing both PS and $\mathrm{MnO}_{4}$. Three of the four experiments shown in Figure 5 were conducted with a constant mass of PS (49 mM) and $0.5 \mathrm{mM}$ 1,4-D with different concentrations of potassium permanganate $(49 \mathrm{mM}, 91 \mathrm{mM}$, and $200 \mathrm{mM})$. The experiment conducted with only $49 \mathrm{mM}$ potassium permanganate and $0.5 \mathrm{mM}$ 1,4-D without addition of PS was assumed to be the control of the experiment (Figure 5). Each of the four experiments showed loss of 1,4-D concentration within $200 \mathrm{~h}$. However, the potassium permanganate control (without PS) only removed about $60 \%$ of the 1,4-D. The experiment with $49 \mathrm{mM}$ PS and $49 \mathrm{mM}$ and $91 \mathrm{mM}$ potassium permanganate removed about $80 \%$, of the 1,4-D. The experiment with $49 \mathrm{mM}$ PS and $200 \mathrm{mM}$ potassium permanganate removed about $100 \%$ of the 1,4-D within $100 \mathrm{~h}$. As greater concentrations of potassium permanganate were added, 1,4-D degradation rate constants were observed to increase, which suggests that $\mathrm{MnO}_{4}$ can be used with PS to increase reactivity and to decrease kinetic limitations for removal of 1,4-D from aqueous solutions. 


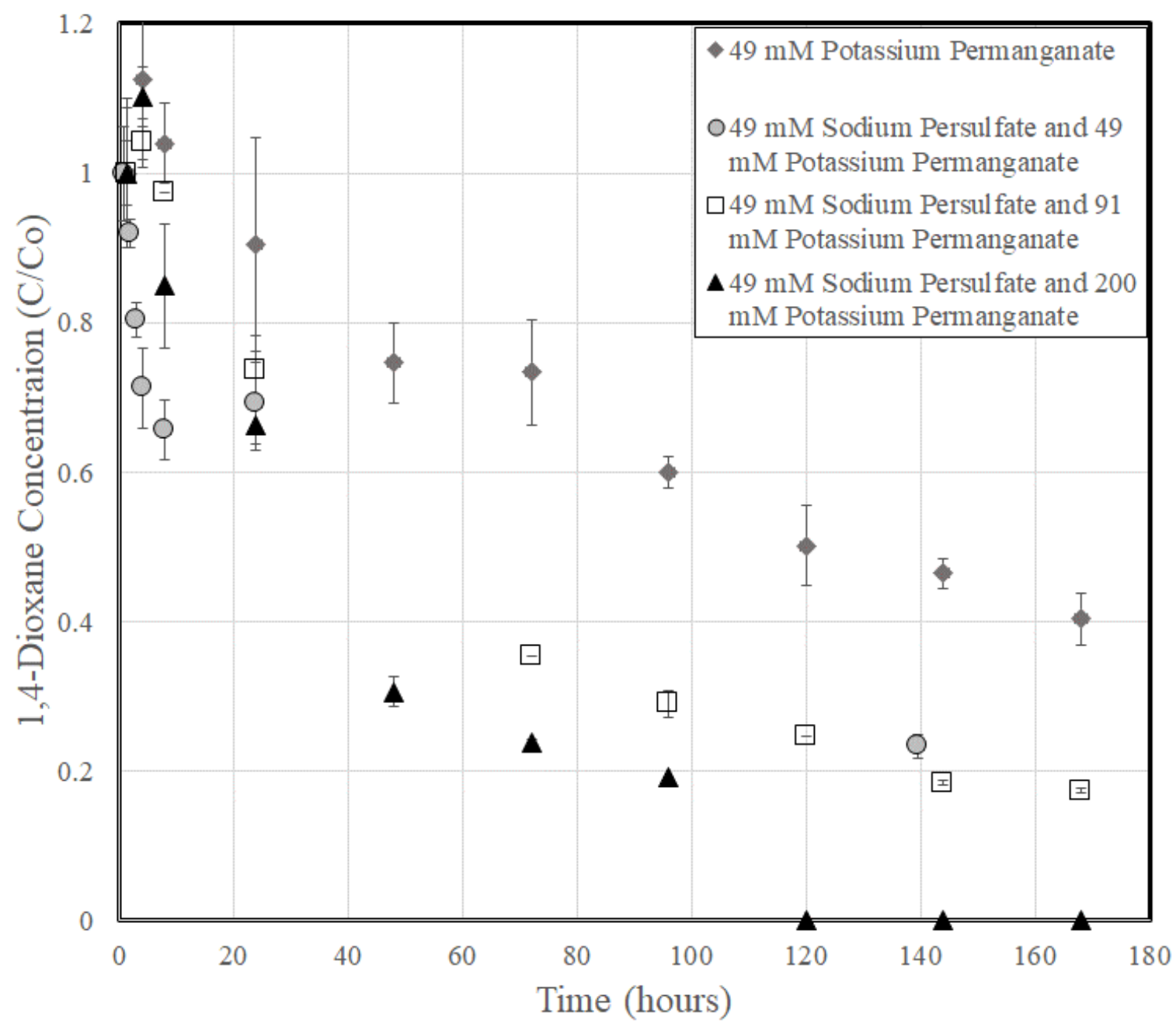

Figure 5. Relative concentration as a function of time illustrating removal kinetics of 1,4-D using PS with various $\mathrm{KMnO}_{4}$ amendment amounts. Relative concentrations were normalized by the initial $0.5 \mathrm{mM}$ of 1,4-D. Error bars represents the standard deviation triplicate replicates.

Table 1. Summary of experimental conditions and resulting 1,4-D removal pseudo 1st order rate constant mean and 95\% C.I. values.

\begin{tabular}{|c|c|c|c|c|c|c|c|c|c|c|}
\hline \multirow{2}{*}{$\begin{array}{c}\begin{array}{c}\text { Contaminant } \\
(\mathrm{mM})\end{array} \\
1,4-\mathrm{D}\end{array}$} & \multicolumn{2}{|c|}{ Oxidants } & \multirow{2}{*}{$\begin{array}{c}\text { Manganese } \\
\begin{array}{c}\text { Dioxide } \\
(\mathrm{g} / \mathrm{L})\end{array}\end{array}$} & \multicolumn{2}{|c|}{$\mathrm{pH}$} & \multirow{2}{*}{$\begin{array}{c}\text { mM } \\
\begin{array}{c}\text { Total } \\
\text { Oxidants }\end{array}\end{array}$} & \multirow{2}{*}{$\begin{array}{c}\begin{array}{c}\text { Oxidant: } \\
\text { Contaminant }\end{array} \\
\text { (Mole Ratio) }\end{array}$} & \multirow{2}{*}{$\begin{array}{c}\begin{array}{c}\text { Rate } \\
\text { Constant }\end{array} \\
k\left(\mathrm{~h}^{-1}\right)\end{array}$} & \multirow{2}{*}{$\begin{array}{c}\begin{array}{c}\text { Rate } \\
\text { Constant }\end{array} \\
95 \% \text { C.I. }\end{array}$} & \multirow{2}{*}{$\begin{array}{c}\text { Regression } \\
\mathbf{R}^{2}\end{array}$} \\
\hline & $\begin{array}{l}\text { Sodium } \\
\text { Persulfate } \\
(\mathrm{mM})\end{array}$ & $\begin{array}{c}\text { Potassium } \\
\text { Permanganate } \\
(\mathrm{mM})\end{array}$ & & Start & End & & & & & \\
\hline \multicolumn{11}{|c|}{ Sodium Persulfate Only } \\
\hline 0.5 & 5 & 0 & 0.0 & 5.2 & 4.0 & 5 & 10 & 0.0003 & \pm 0.0012 & 0.03 \\
\hline 0.5 & 49 & 0 & 0.0 & 4.6 & 2.8 & 49 & 98 & 0.0124 & \pm 0.0010 & 0.98 \\
\hline 0.5 & 49 & 0 & 0.0 & 4.6 & 2.7 & 49 & 98 & 0.0112 & \pm 0.0007 & 0.99 \\
\hline 0.5 & 250 & 0 & 0.0 & 4.0 & 2.3 & 250 & 500 & 0.0352 & \pm 0.0338 & 0.92 \\
\hline \multicolumn{11}{|c|}{ Sodium Persulfate and Manganese Dioxide } \\
\hline 0.5 & 5 & 0 & 100.0 & 5.2 & 3.1 & 5 & 10 & 0.0017 & \pm 0.0007 & 0.57 \\
\hline 0.5 & 49 & 0 & 4.3 & 4.6 & 2.5 & 49 & 98 & 0.0127 & \pm 0.0014 & 0.97 \\
\hline 0.5 & 49 & 0 & 7.9 & 4.5 & 2.5 & 49 & 98 & 0.0109 & \pm 0.0005 & 0.99 \\
\hline 0.5 & 49 & 0 & 11.0 & 4.5 & 2.4 & 49 & 98 & 0.0129 & \pm 0.0008 & 0.99 \\
\hline 0.5 & 49 & 0 & 17.4 & 4.5 & 2.4 & 49 & 98 & 0.0154 & \pm 0.0012 & 0.99 \\
\hline 0.5 & 49 & 0 & 100.0 & 4.4 & 2.4 & 49 & 98 & 0.0083 & \pm 0.0010 & 0.97 \\
\hline 0.5 & 250 & 0 & 17.4 & 4.0 & 2.3 & 250 & 500 & 0.0432 & \pm 0.0194 & 0.95 \\
\hline
\end{tabular}


Table 1. Cont

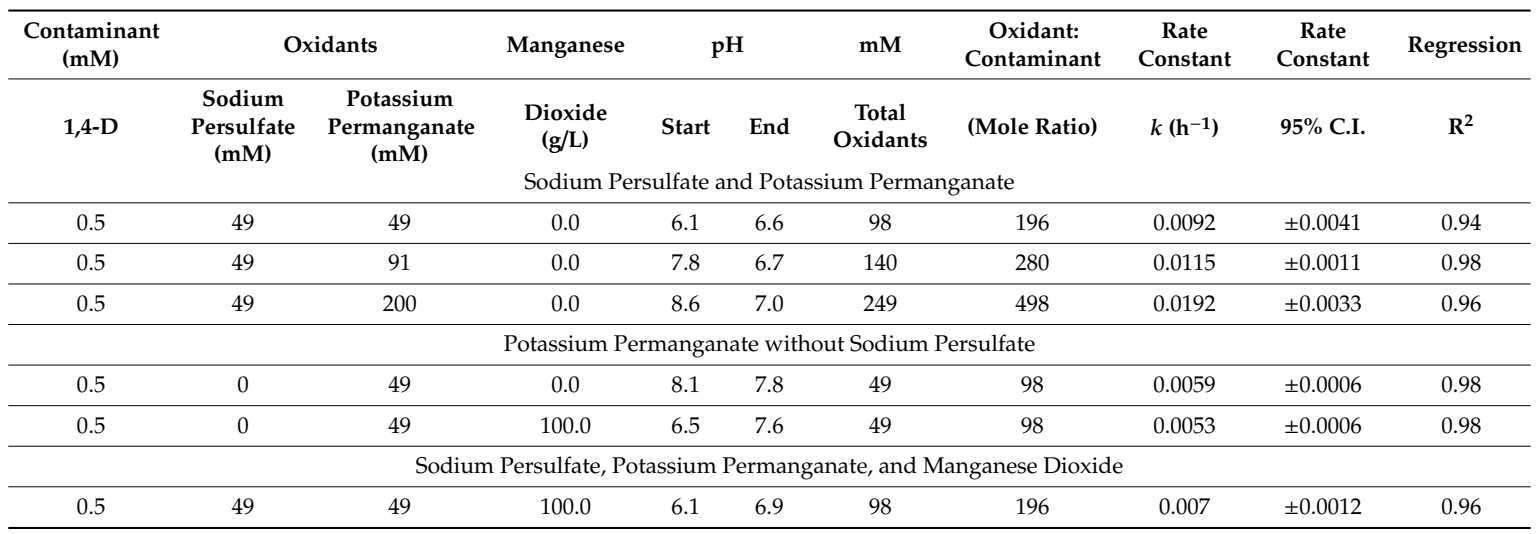

\subsection{Rate Constant Versus Oxidant Content}

A consistent trend of increasing rate constant with increasing oxidant to contaminant ratio is observed (Table 1). This type of trend has been observed for 1,4-D decay upon reaction with a mixture of oxidants termed peroxone activated PS [51], and the rate constants are comparable ( $k\left(\mathrm{MnO}_{2}\right.$ activated PS) $=0.015 \mathrm{~h}^{-1}$ and $k$ (peroxone activated PS) $=0.02 \mathrm{~h}^{-1}$ at 100 oxidant:contaminant ratio). Interestingly, here this trend was observed for PS activated by $\mathrm{MnO}_{2}$ and $\mathrm{KMnO}_{4}$, respectively. Of all the $\mathrm{MnO}_{2}$ experiments conducted, the experiment containing $100 \mathrm{~g} / \mathrm{L}$ of $\mathrm{MnO}_{2}$ had the highest manganese amount and resulted in the lowest 1,4-D-decay rate constant. This is likely attributed to excess $\mathrm{MnO}_{2}$ concentration leading to the rapid decay of PS and loss of potential 1,4-D oxidation, as observed with iron activation [25]. The two largest 1,4-D degradation rate constants were observed with the addition of $250 \mathrm{mM}$ PS with $17.4 \mathrm{~g} / \mathrm{L} \mathrm{MnO}$ and $250 \mathrm{mM}$ PS with no manganese activator, respectively. This suggests that activation may not be needed at the larger PS concentrations, and there may be a potential for self-activation of PS at elevated aqueous PS concentrations.

Table 1 also contains initial and final $\mathrm{pH}$ values for each of the experiments. All of the experiments with $\mathrm{PS}$ activated by $\mathrm{MnO}_{2}$ had $\mathrm{pH}$ values that were initially in the acidic range, and the $\mathrm{pH}$ declined to even more acidic conditions during those experiments. However, all the experiments containing $\mathrm{KMnO}_{4}$, including those with and without PS, maintained $\mathrm{pH}$ values that were approximately neutral. These results indicate that $\mathrm{KMnO}_{4}$ reactivity does not generate acidity, does not likely produce acid catalysis of PS or hydroxyl radical formation, and tends to buffer aqueous solution $\mathrm{pH}$ during oxidation reactions with 1,4-D. Formation of acidic conditions may not be favorable for ISCO due to the potential for subsurface mineral weathering and metal contaminant release.

\subsection{Rate Constant Versus Manganese Content}

Figure 6 presents the 1,4-D pseudo first order rate constant values as a function of manganese amendment content for both $\mathrm{KMnO}_{4}$ and $\mathrm{MnO}_{2}$. As manganese concentration was increased in the batch experiments, a relatively linear increase in the rate constant for 1,4-D degradation occurred. At lower manganese concentrations, $\mathrm{MnO}_{2}$ amended experiments had larger rate constants for 1,4-D degradation compared to $\mathrm{KMnO}_{4}$. At the highest manganese concentration, $\mathrm{KMnO}_{4}$ amendment was observed to result in a higher rate constant for 1,4-D degradation. It is likely that $\mathrm{KMnO}_{4}$ with PS (dual chemical oxidation) acted to oxidize 1,4-D without PS activation, and the increasing reactivity was due to increases the in amount of oxidant added along with any dual oxidant associated synergistic reactivity. These results suggest that both forms of manganese compounds are capable of 1,4-D removal without any significant reaction inhibition effects. 


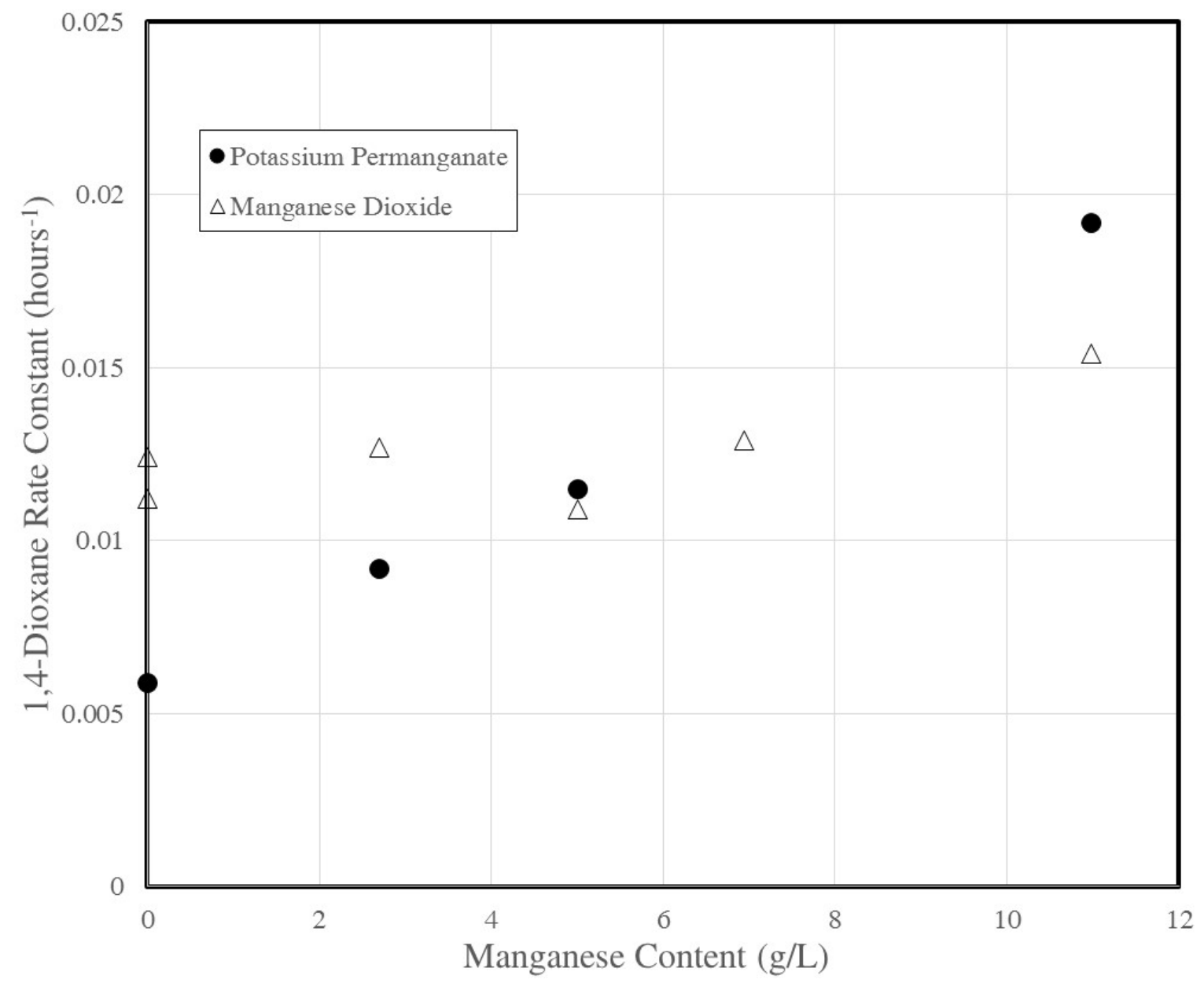

Figure 6. 1,4-D degradation rate constant versus Mn content for experiments conducted with presence of $49 \mathrm{mM}$ PS and different concentrations of $\mathrm{MnO}_{2}$ or $\mathrm{KMnO}_{4}$ amendments.

\subsection{Energy-Dispersive Spectroscopy Characterization of Manganese Dioxide}

Figure 7 presents the results of the $\mathrm{MnO}_{2}$ mineral characterization results from Energy-Dispersive Spectroscopy (EDS) with $\mathrm{MnO}_{2}$ composition expressed as percent atom weight for several elements as a function of increasing PS concentrations. The atom weight percentage for manganese ranged between about $36 \%$ and $47 \%$, with higher percentages measured in the sample that reacted with DI water and the sample that reacted with $5 \mathrm{mM}$ PS compared to the samples that had reacted with the higher PS concentrations. The atom weight percentage of manganese was consistent and negatively correlated with the concentration of PS added to the reactor vial. These results suggest that the $\mathrm{MnO}_{2}$ composition became altered through the activation of PS. We attribute this to changes in manganese valence through activation reactions with PS, and reductions in manganese content of the solid $\mathrm{MnO}_{2}$ may be due to increase aqueous dissolution of manganese upon reaction with PS. 


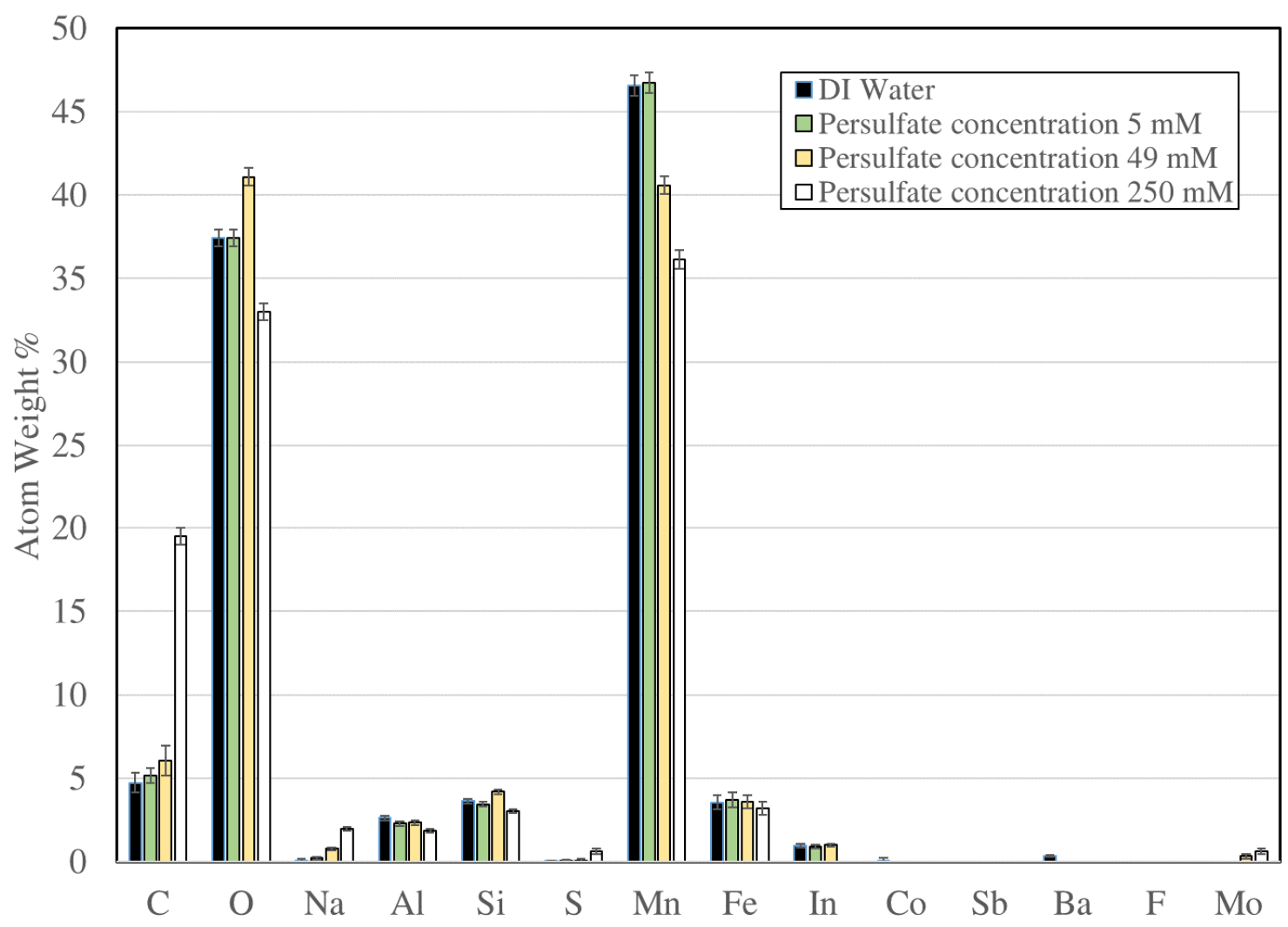

Figure 7. Energy-Dispersive Spectroscopy (EDS) atom weight percentage comparison of $\mathrm{MnO}_{2}$ reacting with DI water and various concentrations of PS.

\section{Summary and Implications}

We quantified and compared PS decay, sulfate production, and removal kinetics for 1,4-D with and without $\mathrm{KMnO}_{4}$ or $\mathrm{MnO}_{2}$ over a range of oxidant to contaminant concentration ratios and manganese amendment concentrations. The results showed that $\mathrm{MnO}_{2}$ activated PS and free radicals were formed, generated sulfate, and therefore increased the rates and potential for degradation of 1,4-D. $\mathrm{KMnO}_{4}$ experiments with PS did not generate observable radical formation even through the binary oxidant mixture did increase reactivity and the kinetics of 1,4-D degradation. Mn amendments in the solid phase as $\mathrm{MnO}_{2}$ and in the aqueous phase as $\mathrm{KMnO}_{4}$ were used in combination with PS, and both amendments resulted in the ability for 1,4-D removal without any measureable inhibition effects, despite manganese valence differences. Rate constants increased with both oxidant to contaminant ratios and also with manganese amendment content. According to US Environmental Protection Agency (EPA), manganese is not considered hazardous, however the EPA does have a Secondary Maximum Contaminant Level standard for manganese in drinking water.

Results suggest that in-situ activation of PS with aquifer materials could be used to enhance its effectiveness for ISCO. Without activation, aqueous PS is quite stable with a half-life of approximately 600 days [33], which suggests a significant potential for injection into the subsurface, transport into groundwater plume areas, and use for ISCO. Oxidant reagent delivery is a primary feasibility constraint for ISCO [52], which is primarily constrained by ubiquitous heterogeneity of hydraulic conductivity [53]. Manganese is common in many minerals, including sulfides, chlorides, oxides, and silicates, and it would likely be naturally present in most contaminated groundwater aquifer systems [54]. It is likely weathered minerals or secondary minerals (e.g., clays or metal oxides) would be more likely to be available and reactive. The oxides are common to soils and aquifers, and these include more than 30 manganese oxide minerals [54]. This suggests that solid-phase manganese may be available in the subsurface for PS activation at many contaminated sites, and therefore that PS 
activation through additional amendment of chemicals or energy may not be required for cleanup of groundwater contaminants using ISCO. The potential would be even greater when considering the combined presence of Fe- and Mn-bearing minerals.

Activation of PS can also be used to enhance its reactivity for efficient contaminant oxidative transformation, and subsurface amendments may be placed in situ to target zones requiring increased reactivity. Targeted subsurface amendments could be used as a reactive barrier for in situ groundwater treatment to decrease contaminant flux released from either sources or at plume boundaries [46]. These amendments could include either organic or inorganic catalysts of PS $[18,22,25,33,55]$. The results presented here suggest that injection of aqueous $\mathrm{KMnO}_{4}$ could increase the manganese content of groundwater, oxidize more labile contaminants (e.g., TCE) to reduce PS-loading requirement. Upon oxidation of organics this would also amend the solid subsurface aquifer materials with solid $\mathrm{MnO}_{2}$, and these amendments would provide in situ activation of PS to enhance ISCO of recalcitrant contaminants including 1,4-D.

Author Contributions: L.B.: Experimental development (kinetics experiments); Data collection and curation; Formal analysis; Investigation; Methodology; Writing — original draft; R.A.M.M.: Data analysis; Data collection and curation (radical trap); Writing-review and editing; N.A.K.: Experimental development; Data collection and curation (radical trap and GC-MS); M.L.B.: Conceptualization; Funding acquisition; Writing-review and editing; K.C.C.: Conceptualization; Data curation; Formal analysis; Funding acquisition; Investigation; Methodology; Project administration; Supervision; Validation; Writing - review and editing. All authors have read and agreed to the published version of the manuscript.

Funding: This research was primarily supported by the US Department of Defense Strategic Environmental Research and Development Program (SERDP) Project ER-2302. The contributions of ML Brusseau were supported by funding from NIEHS (P42 ES04940). Additional support from USDA National Institute of Food and Agriculture (Hatch project 1006845) and the Plant \& Environmental Science Department at NMSU is appreciated.

Acknowledgments: The authors gratefully acknowledge support and assistance of members of the Plant \& Environmental Science Dept. at NMSU. We appreciate the support and assistance of Omar Holguin, Barry Dungan, Barbara Hunter, and members of the Carroll Lab.

Conflicts of Interest: The authors declare no conflict of interest. The funders had no role in the design of the study; in the collection, analyses, or interpretation of data; in the writing of the manuscript, or in the decision to publish the results. Any use of trade, firm, or product names is for descriptive purposes only and does not imply endorsement.

\section{References}

1. Zenker, M.J.; Borden, R.C.; Barlaz, M.A. Occurrence and Treatment of 1,4-Dioxane in Aqueous Environments. Environ. Eng. Sci. 2003, 20, 423-432. [CrossRef]

2. Anderson, R.H.; Anderson, J.K.; Bower, P.A. Co-occurrence of 1,4-dioxane with trichloroethylene in chlorinated solvent groundwater plumes at US Air Force installations: Fact or fiction. Integr. Environ. Assess. Manag. 2012, 8, 731-737. [CrossRef]

3. Adamson, D.T.; Anderson, R.H.; Mahendra, S.; Newell, C.J. Evidence of 1,4-Dioxane Attenuation at Groundwater Sites Contaminated with Chlorinated Solvents and 1,4-Dioxane. Environ. Sci. Technol. 2015, 49, 6510-6518. [CrossRef]

4. IARC. Re-Evaluation of Some Organic Chemicals, Hydrazine and Hydrogen Peroxide; L. International Agency for Research on Cancer: Lyon, France, 1999.

5. Coleman, H.M.; Vimonses, V.; Leslie, G.; Amal, R. Degradation of 1,4-dioxane in water using $\mathrm{TiO}_{2}$ based photocatalytic and $\mathrm{H}_{2} \mathrm{O}_{2} / \mathrm{UV}$ processes. J. Hazard. Mater. 2007, 146, 496-501. [CrossRef]

6. Mohr, T.K.G.; Stickney, J.A.; DiGuiseppi, W.H. Environmental Investigation and Remediation: 1,4-Dioxane and other Solvent Stabilizers; CRC Press Taylor \& Francis: Boca Raton, FL, USA, 2010.

7. U.S.EPA. Integrated Risk Information System (IRIS) on 1,4-Dioxane; National Center for Environmental Assessment, Office of Research and Development: Washington, DC, USA, 2013.

8. DiGuiseppi, W.H.; Whitesides, C. Treatment Options for Remediation of 1,4-Dioxane in Groundwater. Environ. Eng. Am. Acad. Environ. Eng. 2007, 43, 1-7.

9. DiGuiseppi, W.; Walecka-Hutchinson, C.; Hatton, J. 1,4-Dioxane Treatment Technologies. Remediat. J. 2016, 27, 71-92. [CrossRef] 
10. Zhang, S.; Gedalanga, P.B.; Mahendra, S. Advances in bioremediation of 1,4-dioxane-contaminated waters. J. Environ. Manag. 2017, in press. [CrossRef] [PubMed]

11. Adamson, D.T.; Mahendra, S.; Walker, K.L., Jr.; Rauch, S.R.; Sengupta, S.; Newell, C.J. A Multisite Survey to Identify the Scale of the 1,4-Dioxane Problem at Contaminated Groundwater Sites. Environ. Sci. Technol. Lett. 2014, 1, 254-258. [CrossRef]

12. Pollitt, K.J.G.; Kim, J.H.; Peccia, J.; Elimelech, M.; Zhang, Y.; Charkoftaki, G.; Hodges, B.; Zucker, I.; Huang, H.; Deziel, N.C.; et al. 1,4-Dioxane as an emerging water contaminant: State of the science and evaluation of research needs. Sci. Total Environ. 2019, 690, 853-866. [CrossRef] [PubMed]

13. Khan, N.A.; Johnson, M.D.; Kubicki, J.D.; Holguin, F.O.; Dungan, B.; Carroll, K.C. Cyclodextrin-enhanced 1,4-dioxane treatment kinetics with TCE and 1,1,1-TCA using aqueous ozone. Chemosphere 2019, 219, 335-344. [CrossRef] [PubMed]

14. Watts, R.J.; Teel, A.L. Treatment of Contaminated Soils and Groundwater Using ISCO. Pract. Period. Hazard. Toxic Radioact. Waste Manag. 2006, 10, 2-9. [CrossRef]

15. Kolthoff, I.M.; Miller, I.K. The Chemistry of Persulfate. I. The Kinetics and Mechanism of the Decomposition of the Persulfate Ion in Aqueous Medium. J. Am. Chem. Soc. 1951, 73, 3055-3059. [CrossRef]

16. Huling, S.; Pivetz, B. Engineering Issue Paper: In-Situ Chemical Oxidation. Engineering Issue, EPA/600/R-06/072. 2007. Available online: https://clu-in.org/download/contaminantfocus/pcb/ISCO-600R06072.pdf (accessed on 30 October 2020).

17. Cuypers, C.; Grotenhuis, T.; Joziasse, J.; Rulkens, W. Rapid persulfate oxidation predicts PAH bioavailability in soils and sediments. Environ. Sci. Technol. 2000, 34, 2057-2063. [CrossRef]

18. Tsitonaki, A.; Petri, B.; Crimi, M.; Mosbæk, H.; Siegrist, R.L.; Bjerg, P.L. In Situ Chemical Oxidation of Contaminated Soil and Groundwater Using Persulfate: A Review. Crit. Rev. Environ. Sci. Technol. 2010, 40, 55-91. [CrossRef]

19. Zhou, Z.; Liu, X.; Sun, K.; Lin, C.; Ma, J.; He, M.; Ouyang, W. Persulfate-based advanced oxidation processes (AOPs) for organic-contaminated soil remediation: A review. Chem. Eng. J. 2019, 372, 836-851. [CrossRef]

20. Kronholm, J.; Metsälä, H.; Hartonen, K.; Riekkola, M.L. Oxidation of 4-Chloro-3-methylphenol in Pressurized Hot Water/Supercritical Water with Potassium Persulfate as Oxidant. Environ. Sci. Technol. 2001, 35, 3247-3251.

21. Anipsitakis, G.; Dionysiou, D.D. Degradation of Organic Contaminants in Water with Sulfate Radicals Generated by the Conjunction of Peroxymonosulfate with Cobalt. Environ. Sci. Technol. 2003, 37, 4790-4797. [CrossRef]

22. Anipsitakis, G.; Dionysiou, D.D. Radical Generation by the Interaction of Transition Metals with Common Oxidants. Environ. Sci. Technol. 2004, 38, 3705-3712. [CrossRef]

23. Cronk, G. Case study comparison of multiple activation methods for sodium persulfate ISCO treatment. In Proceedings of the Sixth International Conference on Remediation of Chlorinated and Recalcitrant Compounds, Monterey, CA, USA, 19-22 May 2008.

24. Yang, Y.; Pignatello, J.J.; Ma, J.; Mitch, W.A. Comparison of Halide Impacts on the Efficiency of Contaminant Degradation by Sulfate and Hydroxyl Radical-Based Advanced Oxidation Processes (AOPs). Environ. Sci. Technol. 2014, 48, 2344-2351. [CrossRef]

25. Zhong, H.; Brusseau, M.L.; Wang, Y.; Yan, N.; Quig, L.; Johnson, G.R. In-situ activation of persulfate by iron filings and degradation of 1,4-dioxane. Water Res. 2015, 83, 104-111. [CrossRef]

26. Ahmad, M.; Teel, A.L.; Watts, R.J. Persulfate activation by subsurface minerals. J. Contam. Hydrol. 2010, 115, 34-45. [CrossRef] [PubMed]

27. Teel, A.L.; Ahmad, M.; Watts, R.J. Persulfate activation by naturally occurring trace minerals. J. Hazard. Mater. 2011, 196, 153-159. [CrossRef]

28. Yu, M.; Teel, A.L.; Watts, R.J. Activation of Peroxymonosulfate by Subsurface Minerals. J. Contam. Hydrol. 2016, 191, 33-43. [CrossRef] [PubMed]

29. Fang, G.; Chen, X.; Wu, W.; Liu, C.; Dionysiou, D.D.; Fan, T.; Wang, Y.; Zhu, C.; Zhou, D. Mechanisms of Interaction between Persulfate and Soil Constituents: Activation, Free Radical Formation, Conversion, and Identification. Environ. Sci. Technol. 2018, 52, 14352-14361. [CrossRef] [PubMed]

30. Zhu, S.; Li, X.; Kang, J.; Duan, X.; Wang, S. Persulfate Activation on Crystallographic Manganese Oxides: Mechanism of Singlet Oxygen Evolution for Nonradical Selective Degradation of Aqueous Contaminants. Environ. Sci. Technol. 2019, 53, 307-315. [CrossRef] [PubMed] 
31. Huang, J.Z.; Zhang, H.C. Mn-based catalysts for sulfate radical-based advanced oxidation processes: A review. Environ. Int. 2019, 133, 105141. [CrossRef]

32. Lee, J.; von Gunten, U.; Kim, J.H. Persulfate-Based Advanced Oxidation: Critical Assessment of Opportunities and Roadblocks. Environ. Sci. Technol. 2020, 54, 3064-3081. [CrossRef]

33. Liu, H.; Bruton, T.A.; Doyle, F.M.; Sedlak, D.L. In Situ Chemical Oxidation of Contaminated Groundwater by Persulfate: Decomposition by $\mathrm{Fe}(\mathrm{III})$ - and $\mathrm{Mn}(\mathrm{IV})$-Containing Oxides and Aquifer Materials. Environ. Sci. Technol. 2014, 48, 10330-10336. [CrossRef]

34. Yan, N.; Liu, F.; Xue, Q.; Brusseau, M.L.; Liu, Y.; Wang, J. Degradation of trichloroethene by siderite-catalyzed hydrogen peroxide and persulfate: Investigation of reaction mechanisms and degradation products. Chem. Eng. J. 2015, 274, 61-68. [CrossRef]

35. Li, W.; Orozco, R.; Camargos, N.; Liu, H. Mechanisms on the Impacts of Alkalinity, pH, and Chloride on Persulfate-Based Groundwater Remediation. Environ. Sci. Technol. 2017, 51, 3948-3959. [CrossRef]

36. Yan, N.; Zhong, H.; Brusseau, M.L. The natural activation ability of subsurface media to promote in-situ chemical oxidation of 1,4-dioxane. Water Res. 2019, 149, 386-393. [CrossRef]

37. Urynowicz, M.A.; Siegrist, R.L. Chemical degradation of TCE DNAPL by Permanganate. In Chemical Oxidation and Reactive Barriers: Remediation of Chlorinated and Recalcitrant Compounds; Wickramanayake, G.B., Gavaskar, A.R., Chen, A.S.C., Eds.; Battelle Press: Columbus, OH, USA, 2000; pp. 75-82.

38. Reitsma, S.; Marshall, M. Experimental study of oxidation of pooled NAPL. In Chemical Oxidation and Reactive Barriers: Remediation of Chlorinated and Recalcitrant Compounds; Wickramanayake, G.B., Gavaskar, A.R., Chen, A.S.C., Eds.; Battelle Press: Columbus, OH, USA, 2000; pp. 25-32.

39. Conrad, S.H.; Glass, R.J.; Peplinski, W.J. Bench-scale visualization of DNAPL remediation processes in analog heterogeneous aquifers: Surfactant floods and in situ oxidation using permanganate. J. Contam. Hydrol. 2002, 58, 13-49. [CrossRef]

40. MacKinnon, L.K.; Thomson, N.R. Laboratory-scale in situ chemical oxidation of a perchloroethylene pool using permanganate. J. Contam. Hydrol. 2002, 56, 49-74. [CrossRef]

41. Li, X.D.; Schwartz, F.W. DNAPL mass transfer and permeability reduction during in situ chemical oxidation with permanganate. Geophys. Res. Lett. 2004, 31. [CrossRef]

42. Li, X.D.; Schwartz, F.W. DNAPL remediation with in situ chemical oxidation using potassium permanganate. II. Increasing removal efficiency by dissolving Mn oxide precipitates. J. Contam. Hydrol. 2004, 68, 269-287. [CrossRef]

43. Heiderscheidt, J.L.; Siegrist, R.L.; Illangasekare, H. Intermediate-scale 2D experimental investigation of in situ chemical oxidation using potassium permanganate for remediation of complex DNAPL source zones. J. Contam. Hydrol. 2008, 102, 3-16. [CrossRef] [PubMed]

44. Marble, J.C.; Carroll, K.C.; Janousek, H.; Brusseau, M.L. In situ oxidation and associated mass-fluxreduction/mass-removal behavior for systems with organic liquid located in lower-permeability sediments. J. Contam. Hydrol. 2010, 117, 82-93. [CrossRef] [PubMed]

45. Brusseau, M.L.; Carroll, K.C.; Allen, T.; Baker, J.; DiGuiseppi, W.; Hatton, J.; Morrison, C.; Russo, A.; Berkompas, J. Impact of In Situ Chemical Oxidation on Contaminant Mass Discharge: Linking Source-Zone and Plume-Scale Characterizations of Remediation Performance. Environ. Sci. Technol. 2011, 45, 5352-5358. [CrossRef] [PubMed]

46. Marble, J.C.; Brusseau, M.L.; Carroll, K.C.; Plaschke, M.; Fuhrig, L.; Brinker, F. Application of a Persistent Dissolved-Phase Reactive Treatment Zone for Mitigation of Mass Discharge from Sources Located in Lower-Permeability Sediments. Water Air Soil Pollut. 2014, 225, 2198. [CrossRef]

47. Johnson, M.D.; Hornstein, B.J. The kinetics and mechanism of the ferrate(VI) oxidation of hydroxylamines. Inorg. Chem. 2003, 42, 6923-6928. [CrossRef]

48. Wilkins, R.G. Kinetics and Mechanism of Reactions of Transition Metal Complexes; Wiley-VCH Verlag GmbH \& Co. KGaA: Weinheim, Germany, 2002.

49. Liang, C.; Huang, C.F.; Mohanty, N.; Kurakalva, R.M. A rapid spectrophotometric determination of persulfate anion in ISCO. Chemosphere 2008, 73, 1540-1543. [CrossRef]

50. Sethna, S.M. The ELBS Persulfate Oxidation. Chem. Rev. 1951, 49, 91-101. [CrossRef]

51. Eberle, D.; Ball, R.; Boving, T.B. Peroxone activated persulfate treatment of 1,4-dioxane in the presence of chlorinated solvent co-contaminants. Chemosphere 2016, 144, 728-735. [CrossRef] [PubMed] 
52. Khan, N.A.; Carroll, K.C. Natural attenuation method for contaminant remediation reagent delivery assessment for in situ chemical oxidation using aqueous ozone. Chemosphere 2020, 247, 125848. [CrossRef] [PubMed]

53. Yeh, T.-C.J.; Khaleel, R.; Carroll, K.C. Flow through Heterogeneous Geologic Media; Cambridge University Press: New York, NY, USA, 2015.

54. Post, J.E. Manganese oxide minerals: Crystal structures and economic and environmental significance. Proc. Natl. Acad. Sci. USA 1999, 96, 3447-3454. [CrossRef]

55. Chen, H.; Carroll, K.C. Metal-free catalysis of persulfate activation and organic-pollutant degradation by nitrogen-doped graphene and aminated graphene. Environ. Pollut. 2016, 215, 96-102. [CrossRef]

Publisher's Note: MDPI stays neutral with regard to jurisdictional claims in published maps and institutional affiliations.

(C) 2020 by the authors. Licensee MDPI, Basel, Switzerland. This article is an open access article distributed under the terms and conditions of the Creative Commons Attribution (CC BY) license (http://creativecommons.org/licenses/by/4.0/). 